Research Article

\title{
Simulation Study on Dynamics of Hydraulic Turbines Used in Drilling Engineering
}

\author{
Yijin Zeng, ${ }^{1,2}$ Jin Wang $\mathbb{D}^{3,4}$ Shidong Ding, ${ }^{1,2}$ Haobo Zhou, ${ }^{1,2}$ Yanbin Zang, ${ }^{1,2}$ \\ and Fangtao $\mathrm{Li}^{3,4}$ \\ ${ }^{1}$ State Key Laboratory of Shale Oil and Gas Enrichment Mechanisms and Effective Development, Beijing, China \\ ${ }^{2}$ Sinopec Research Institute of Petroleum Engineering, Beijing 000101, China \\ ${ }^{3}$ School of Engineering and Technology, China University of Geosciences, Beijing 100083, China \\ ${ }^{4}$ Key Laboratory of Deep Geodrilling Technology, Ministry of Land and Resources, Beijing 100083, China
}

Correspondence should be addressed to Jin Wang; wjzym286@163.com

Received 30 June 2020; Revised 13 July 2020; Accepted 17 August 2020; Published 26 August 2020

Academic Editor: Wenjun Huang

Copyright (c) 2020 Yijin Zeng et al. This is an open access article distributed under the Creative Commons Attribution License, which permits unrestricted use, distribution, and reproduction in any medium, provided the original work is properly cited.

Hydroturbines have a very wide range of applications, which are commonly found in wind turbines, water turbines, aero engines, etc. This paper provided a detailed turbine design and a design method of turbine blade shape. Using the CFD (computational fluid dynamics) method, based on the realizable $k-\varepsilon$ turbulence model and Euler multiphase flow model, the effects of different external loads, blade numbers, blade installation angles, and flow rates on the force condition of turbine and the influence of different solid contents, particle sizes, and densities on turbine performance were studied. The simulation results show that, under the action of fluid, when the starting torque of turbine is larger than the external load, the turbine starts to move, the angular velocity increases until it remains constant, the absolute value of impact force decreases, and the impact torque decreases until it is equal to the external load; while the starting torque of turbine is smaller than the external load, the turbine stays still. The increase of the particle size, content, and density of the solid phase will lead to an increase in the torque and pressure drop of the turbine and ultimately leads to the increase of turbine input, output power, and efficiency.

\section{Introduction}

Hydroturbines have a very wide range of applications, which are commonly found in wind turbines, water turbines, aero engines, etc. $[1,2]$. Blade components also have important applications in drilling engineering and are often used as turbine power generators and turbine drilling tools as downhole power devices [3]. Underground turbine generator is one of the common underground power supplies. The downhole turbine generator acts as an axial flow impeller, and the turbine is rotated by the impact of the drilling fluid circulating in the downhole. At the same time, the magnetic coupling of the magnetic coupler drives the permanent magnet generator to generate electricity, thereby achieving the function of continuous power supply for downhole instruments. Turbine drilling tools $[1,2,4]$ also belong to the typical blade-type axial flow machinery, which works by means of the interaction between the blades and the fluid medium and realizes the conversion of hydraulic energy and mechanical energy based on the principle of momentum moment and finally the speed and torque of the turbine shaft output.

With the increasing difficulty of drilling and production in oil and gas fields, downhole drilling tools have been developed rapidly, their power gradually increases, the working time becomes longer and longer, and harsh underground wells, horizontal wells, multibranch wells, LWD (logging while drilling) measuring instruments, and downhole intelligent tools such as mud loggers and rotary guides are indispensable $[5,6]$. These instruments and tools require electrical energy to work. With the increase of measurement parameters and the complexity of downhole control mechanisms, the requirements for power supply are becoming higher and higher. Therefore, it is very important to reliably provide continuous and stable electrical energy for underground instruments and tools. 
In the purely mechanical structure, fluid pressure [7] is often used as a source of power, compared to the motor drive system; hydraulic system has higher power density [8]. The fluid power technology can achieve high power output with low system mass compared to other common powertrain technologies [9]. Hydraulic turbine [10-12] is the most common energy conversion device that converts hydraulic pressure into rotary motion, which is commonly used [2,13-24] in wind energy, hydraulic turbines, hydraulic motors, etc. Ge et al. [15] studied the Reynolds number of airfoil aerodynamic performances and its influence on the optimal design of wind turbine rotor and discussed the maximum power coefficient; Hansen [16] developed and tested an airfoil optimization method for wind turbine applications, which can control the performance loss caused by leading edge contamination. In view of the failure of traditional fluid machinery in supersonic flow, Paniagua et al. [17] designed and analyzed advanced high-sonic axial flow turbines. Pereiras et al. [18] calculated the efficiency of the twin-turbine structure based on the results of the numerical model and paid attention to the influence of the turbine's torque and flow rate under the reverse mode conditions. Kwon et al. [19] used the Rayleigh-Ritz hypothesis model method to analyze a turbine generator, determined the resonant frequency and intensity of the rotating multipackage blade system excited by multiple nozzle forces, and studied the influence of different parameters such as the number of nozzles and damping coefficient on the system response. Müller et al. [20] analyzed the wind energy converter and discussed the modern transformation of this traction type energy converter for building integration. Lanzafame and Messina [21] improved the blade element momentum theory and established a mathematical model for the design of hydrodynamic wind turbines at low wind speed, which is used to optimize the performance of the rotor. The axial flow Wells turbine [22] is widely operated in most energy stations. The principle of operation of the Wells turbine is based on aerodynamics, and several variants of the Wells turbine have been proposed and developed $[23,24]$. The performance and shape of Wells turbines have been optimized by numerical [25] and experimental [26] methods for each of the sea states [27]. A novel twin-rotor radialinflow air turbine was recently proposed [28], which has two sets of rotor blades equipped on a common shaft that are axially offset from each other. Another new topology that uses twinunidirectional turbines has been proposed and studied [29].

This paper provided a detailed turbine design and design method of turbine blade shape. At present, the research on downhole turbines is static. In this paper, by using FLUENT software and sliding mesh method, UDF (user-defined function) file is compiled to simulate the dynamic performance of downhole turbine. The effects of external load, number of blades, flow rate, and blade installation angle on the hydrodynamic performance of downhole turbine are studied, and the start-up characteristics and movement process of downhole turbine are analyzed.

\section{Modeling and Methods}

In the drilling industry, downhole hydraulic turbine is often used as the power mechanism of downhole drilling tools. For example, as a part of the turbine generator, it provides power for the underground electronic mechanism. It can also be used as the rotor of turbodrill to drive other mechanical structures directly by using the rotating characteristics of the turbine. The downhole turbine can be divided into cascade turbine and spiral turbine according to its form. In this paper, the traditional cascade turbine is used to design the hydraulic turbine.

2.1. Turbine Cascade Flow Parameter Design. Turbine motion is a dynamic process. The turbine is passively forced to rotate under the action of fluid. The speed of the turbine is related to the flow rate, turbine structure parameters, and the external load imposed on the turbine.

Turbine cascade flow parameter design refers to the calculation of the inlet and outlet liquid flow angle of the blade. Turbine stator and rotor blades have different flow angles at the inlet and outlet, and the law of liquid flow rate change in the turbine is also different, which will cause changes in performance parameters such as turbine output torque, speed, and power.

According to the unary flow theory [2], the absolute velocity, relative velocity, and circumferential velocity of the blade inlet and outlet under the nonimpact conditions constitute the blade inlet and outlet velocity triangle (as shown in Figure 1). The triangle of blade inlet and outlet speed is closely related to the characteristics of the turbine. According to the design parameters of the driving turbine and the geometrical dimensions of the turbine pair, the inlet and outlet speed triangles of the blades are determined, and the relationship between the angles of the triangles determines the parameters such as the flow angle.

Euler's formula for univariate flow theory is

$$
\begin{aligned}
& T_{i}=\rho Q R\left(C_{1 u}-C_{2 u}\right) . \\
& N_{i}=\rho Q u\left(C_{1 u}-C_{2 u}\right) . \\
& H_{i}=\frac{u}{g}\left(C_{1 u}-C_{2 u}\right),
\end{aligned}
$$

where $T_{i}, N_{i}$, and $H_{i}$ represent the torque, power, and conversion head of the single-stage turbine, respectively, $Q$, $g, \rho$, and $R$ represent the inlet flow rate, gravity acceleration, working fluid density, and equivalent average radius of overflow, $u$ is equivalent of the circumferential speed at the average flow radius, and $C_{1 u}$ and $C_{2 u}$ are the projections of the absolute inlet and outlet speeds $C_{1}$ and $C_{2}$ on the circumferential speed, respectively.

In the speed triangle at the inlet and outlet of the rotor blade, there are the following equations:

$$
\begin{aligned}
C_{z} & =\frac{Q}{F}, \\
u & =\frac{\pi n R}{30}, \\
C_{1 u} & =C_{z} \operatorname{ctg} \alpha_{1},
\end{aligned}
$$




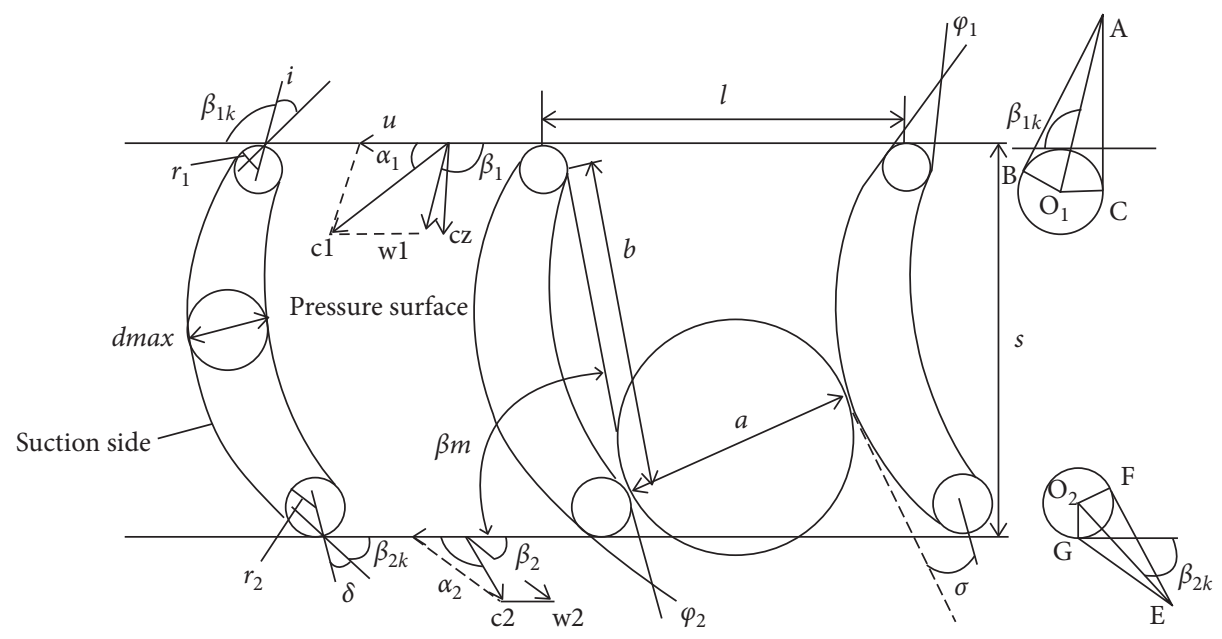

Figure 1: Turbine cascade parameters. $\alpha_{1}$ and $\alpha_{2}$ : the outlet angle and inlet angle of turbine stator working fluid flow. $\beta_{1}$ and $\beta_{2}$ : inlet and outlet angles of turbine rotor working fluid flow. $\alpha_{1 k}$ and $\alpha_{2 k}$ : inlet structure angle and outlet structure angle of turbine stator. $\beta_{1 k}$ and $\beta_{2 k}$ : inlet structure angle and outlet structure angle of turbine rotor. $c_{1}$ : the absolute flow velocity at the inlet and outlet of the turbine rotor. $c_{2}$ : the absolute flow velocity at the turbine stator inlet and rotor outlet. $c_{1 u}$ : circumferential partial velocity of the absolute flow velocity at the inlet of the turbine rotor. $c_{2 u}$ : the circumferential component of the absolute flow velocity at the outlet of the turbine rotor. $c_{1 z}$ : the axial velocity component of the absolute flow velocity at the inlet of the turbine rotor.

$$
C_{2 u}=u-C_{z} \operatorname{ctg} \beta_{2}
$$

where $F$ is the cross-sectional area of the flow path perpendicular to the axial velocity, $F=2 \pi B R \varphi ; \varphi$ is the clogging factor affected by the thickness of the blade, which is generally 0.9. $B$ is the radial width of the flow channel, and $C_{Z}$ is the axial flow velocity. Substituting (5) and (6) into (1), (2), and (3), respectively, we can obtain

$$
\begin{aligned}
& T_{i}=\rho Q R\left(C_{z} \operatorname{ctg} \alpha_{1}+C_{z} \operatorname{ctg} \beta_{2}-u\right), \\
& N_{i}=\rho Q u\left(C_{z} \operatorname{ctg} \alpha_{1}+C_{z} \operatorname{ctg} \beta_{2}-u\right), \\
& H_{i}=\frac{u}{g}\left(C_{z} \operatorname{ctg} \alpha_{1}+C_{z} \operatorname{ctg} \beta_{2}-u\right) .
\end{aligned}
$$

According to the import and export speed triangle, the fixed turbine, rotor inlet and outlet angles, and dimensionless coefficients have the following relationship:

$$
\begin{aligned}
& \operatorname{ctg} \alpha_{1}=\frac{C_{1 u}}{C_{z}}=\frac{1}{\overline{C_{z}}}\left(m_{a}+\frac{\overline{C_{u}}}{2}\right), \\
& \operatorname{ctg} \alpha_{2}=\frac{C_{2 u}}{C_{z}}=\frac{1}{\overline{C_{z}}}\left(m_{a}-\frac{\overline{C_{u}}}{2}\right), \\
& \operatorname{ctg} \beta_{1}=\frac{w_{1 u}}{C_{z}}=\frac{1}{\overline{C_{z}}}\left[1-\left(m_{a}+\frac{\overline{C_{u}}}{2}\right)\right], \\
& \operatorname{ctg} \beta_{2}=\frac{w_{2 u}}{C_{z}}=\frac{1}{\overline{C_{z}}}\left[1-\left(m_{a}-\frac{\overline{C_{u}}}{2}\right)\right], \\
& \operatorname{tg} \beta_{m}=\frac{2}{\operatorname{ctg} \beta_{1}+\operatorname{ctg} \beta_{2}}, \\
& \operatorname{tg} \alpha_{m}=\frac{2}{\operatorname{ctg} \alpha_{1}+\operatorname{ctg} \alpha_{2}},
\end{aligned}
$$

where $\bar{C}_{z}$ is the axial velocity coefficient, $C_{z}$ is the axial flow velocity, and $\mathrm{u}$ is the peripheral speed, $\bar{C}_{z}=C_{z} / u ; m_{a}$ is the impact degree coefficient; $C_{m u}$ is the component of the average value of the absolute velocity of the entrance and exit in the direction of the circumferential velocity, $m_{a}=C_{m u} / u$; $\bar{C}_{u}=C_{1 u}-C_{2 u} / u$ is circulation coefficient; as the circulation coefficient increases, the turbine output torque and turbine blade curvature also increase.

2.2. Blade Profile Model. The turbine blade flow channel is constricted; that is, the flow channel from the blade inlet to the throat should be continuously and smoothly contracted, and the diffusion should be minimized from the throat to the trailing edge. The blade profile has a great influence on the flow field, mainly by changing the velocity and pressure distribution near the blade surface to change the flow field across the blade flow channel. It is generally expected that the blade surface speed and pressure distribution should change smoothly. The shape of the blade must ensure that the profile has a continuous curvature; that is, the profile of the pressure surface and the suction surface must have a continuous third derivative.

The traditional blade pressure surface and suction surface curves are arc, parabola, double button, logarithmic spiral and hyperbola, and quadratic curve. There are five main combinations of these curves when forming the turbine blade type: (1) completely composed of circular arcs, (2) composed of circular arcs and hyperbolic spirals, (3) composed of double curved lines, (4) composed of parabola, and (5) composed of parabola and arc.

These combined profiles often have discontinuous curvature points, which reduces turbine performance. In order to solve this problem, the blade pressure surface and suction surface profile should be in a single profile rather than in a combined profile and have a continuous 
third-order derivative; high-order parameter splines, highorder polynomials, and high-order Bezier are the main selection objects.

In general, the shape of the blade is designed with a fifthdegree polynomial.

Establish the coordinates as shown in Figure 2. Let the pressure and suction surface profiles of the blade be $y_{p}=f(x)$ and $y_{s}=g(x)$, respectively; they have the following form:

$$
\begin{aligned}
& y_{P}=a_{0}+a_{1} x+a_{2} x^{2}+a_{3} x^{3}+a_{4} x^{4}+a_{5} x^{5}, \\
& y_{S}=b_{0}+b_{1} x+b_{2} x^{2}+b_{3} x^{3}+b_{4} x^{4}+b_{5} x^{5} .
\end{aligned}
$$

The first derivative is

$$
\begin{aligned}
& y_{p}^{\prime}=a_{1}+2 a_{2} x+3 a_{3} x^{2}+4 a_{4} x^{3}+5 a_{5} x^{4}, \\
& y_{s}^{\prime}=b_{1}+2 b_{2} x+3 b_{3} x^{2}+b a_{4} x^{3}+5 b_{5} x^{4} .
\end{aligned}
$$

The second derivative is

$$
\begin{aligned}
& y_{p}^{\prime \prime}=2 a_{2}+6 a_{3} x+12 a_{4} x^{2}+20 a_{5} x^{3}, \\
& y_{s}^{\prime \prime}=2 b_{2}+6 b_{3} x+12 b_{4} x^{2}+20 b_{5} x^{3} .
\end{aligned}
$$

Let the coordinates, first and second derivatives of the first point on the pressure surface, be $\left(x_{\mathrm{p} 1}, y_{\mathrm{p} 1}\right), y_{p 1}^{\prime}$ and $y_{p 1}^{\prime \prime}$; let the coordinates, first and second derivatives of the last point on the pressure surface, be $\left(x_{p n}, y_{p n}\right), y_{p n}^{\prime}$ and $y_{p n}^{\prime \prime}$; let the coordinates, first and second derivatives of the first point on the suction side, be $\left(x_{\mathrm{s} 1}, y_{\mathrm{s} 1}\right), y_{s 1}^{\prime}$ and $y_{s 1}^{\prime \prime}$; let the coordinates, first and second derivatives of the last point on the suction side, be $\left(x_{\mathrm{sn}}, y_{\mathrm{sn}}\right), y_{s n}^{\prime}$ and $y_{s n}^{\prime \prime}$.

Then, we can obtain the following two linear equations:

$$
\left[\begin{array}{cccccc}
1 & x_{p 1} & x_{p 1}^{2} & x_{p 1}^{3} & x_{p 1}^{4} & x_{p 1}^{5} \\
1 & x_{p n} & x_{p n}^{2} & x_{p n}^{3} & x_{p n}^{4} & x_{p n}^{5} \\
0 & 1 & 2 x_{p 1} & 3 x_{p 1}^{2} & 4 x_{p 1}^{3} & 5 x_{p 1}^{4} \\
0 & 1 & 2 x_{p n} & 3 x_{p n}^{2} & 4 x_{p n}^{3} & 5 x_{p n}^{4} \\
0 & 0 & 2 & 6 x_{p 1} & 12 x_{p 1}^{2} & 20 x_{p 1}^{3} \\
0 & 0 & 2 & 6 x_{p n} & 12 x_{p n}^{2} & 20 x_{p n}^{3}
\end{array}\right]\left[\begin{array}{c}
a_{0} \\
a_{1} \\
a_{2} \\
a_{3} \\
a_{4} \\
a_{5}
\end{array}\right]=\left[\begin{array}{c}
y_{p 1} \\
y_{p n} \\
y_{p 1}^{\prime} \\
y_{p n}^{\prime} \\
y_{p 1}^{\prime \prime} \\
y_{p n}^{\prime \prime}
\end{array}\right] .
$$

$$
\left[\begin{array}{cccccc}
1 & x_{s 1} & x_{s 1}^{2} & x_{s 1}^{3} & x_{s 1}^{4} & x_{s 1}^{5} \\
1 & x_{s n} & x_{s n}^{2} & x_{s n}^{3} & x_{s n}^{4} & x_{s n}^{5} \\
0 & 1 & 2 x_{s 1} & 3 x_{s 1}^{2} & 4 x_{s 1}^{3} & 5 x_{s 1}^{4} \\
0 & 1 & 2 x_{s n} & 3 x_{s n}^{2} & 4 x_{s n}^{3} & 5 x_{s n}^{4} \\
0 & 0 & 2 & 6 x_{s 1} & 12 x_{s 1}^{2} & 20 x_{s 1}^{3} \\
0 & 0 & 2 & 6 x_{s n} & 12 x_{s n}^{2} & 20 x_{s n}^{3}
\end{array}\right]\left[\begin{array}{l}
b_{0} \\
b_{1} \\
b_{2} \\
b_{3} \\
b_{4} \\
b_{5}
\end{array}\right]=\left[\begin{array}{c}
y_{s 1} \\
y_{s n} \\
y_{s 1}^{\prime} \\
y_{s n}^{\prime} \\
y_{s 1}^{\prime \prime} \\
y_{s n}^{\prime \prime}
\end{array}\right]
$$

Solve the linear equations (12) and (13) to obtain the blade pressure surface and suction surface profile.

Using the parameters in Table 1, combined with (12) and (13), we obtain that the pressure surface equation is

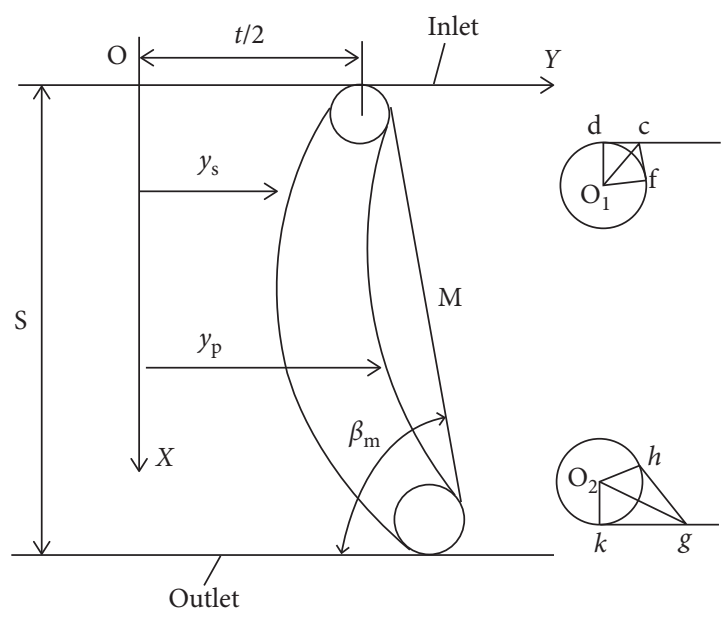

FIgURE 2: Schematic diagram of coordinate relationship.

TABLE 1: Basic parameters of downhole turbine.

\begin{tabular}{lc}
\hline Parameter & Value \\
\hline Leading edge radius $r_{1}$ & $0.8 \mathrm{~mm}$ \\
Trailing edge radius $r_{2}$ & $0.4 \mathrm{~mm}$ \\
Axial height $H$ & $22.5 \mathrm{~mm}$ \\
Installation angle $\beta_{m}$ & $40^{\circ}$ \\
Chord $B$ & $28.72 \mathrm{~mm}$ \\
Maximum thickness a/B & 0.4 \\
Center line of blade profile $L_{n}$ & $22.28 \mathrm{~mm}$ \\
Blade front cone angle $\gamma_{1}$ & $14^{\circ}$ \\
Blade back cone angle $\gamma_{2}$ & $12^{\circ}$ \\
Relative pitch $\bar{t}$ & 0.75 \\
\hline
\end{tabular}

$$
\begin{aligned}
y_{p}= & 7.15509+0.203899 x-0.006416 x^{2}+0.0034401 x^{3} \\
& -0.00008998 x^{4}+0.000000326 x^{5} .
\end{aligned}
$$

The suction surface equation is

$$
\begin{aligned}
y_{s}= & 5.73498-0.03981 x-0.0097496 x^{2}+0.004411 x^{3} \\
& -0.00009699 x^{4}+-0.00000000316 x^{5} .
\end{aligned}
$$

\subsection{Fluid Simulation Model}

2.3.1. Fluid Motion Equations. A flowing fluid follows the law of conservation of mass, momentum, and energy. However, it is very difficult to solve the velocity field and pressure field in complex flows accurately. The computational fluid dynamics (CFD) method can be used to solve the approximate solution to satisfy the engineering application. The accuracy of CFD methods has been verified in many fields [30-32]. This paper employed numerical simulation tools to demonstrate the results of the theoretical analysis and to study the variation of geometric parameters.

The working medium of the turbine is liquid. Generally, the liquid is regarded as an incompressible fluid. The basic 
equations describing the flow of incompressible fluid in the turbine include the continuity equation and the equation of motion. The absolute motion continuity equation and motion in the cylindrical coordinate system are used for the stator, and the rotor adopts the relative motion continuity equation and motion equation under the cylindrical standard system.

Using the traditional numerical method to solve the fluid flow in the turbine stator and rotor across the blade flow channel is very complicated; generally, there is no analytical solution; as a result, CFD method is used.

2.3.2. Simulation Turbulence Model. A flow simulation was carried out using the software of ANSYS FLUENT 19.0, which uses the finite-element numerical method for solving the Reynolds-averaged Navier-Stokes equations by means of the pressure-based solver. The whole 3D geometry model of the turbine was established using ANSYS Workbench, and grids were generated using the preprocessing software ICEM-CFD.

The $\mathrm{k}-\varepsilon$ realizable model is selected. The transport equations of turbulent kinetic energy and dissipation rate are as follows:

$$
\begin{aligned}
\frac{\partial}{\partial t}(\rho k)+\frac{\partial}{\partial x_{i}}\left(\rho k u_{i}\right)= & \frac{\partial}{\partial x_{i}}\left[\left(\mu+\frac{\mu_{t}}{\sigma_{k}}\right) \frac{\partial k}{\partial x_{j}}\right]+G_{k}+G_{b} \\
& -\rho \varepsilon-Y_{M}, \\
\frac{\partial}{\partial t}(\rho \varepsilon)+\frac{\partial}{\partial x_{i}}\left(\rho \varepsilon u_{i}\right)= & \frac{\partial}{\partial x_{j}}\left[\left(\mu+\frac{\mu_{t}}{\sigma_{\varepsilon}}\right) \frac{\partial \varepsilon}{\partial x_{j}}\right]+\rho C_{1} E \varepsilon \\
& -C_{2} \rho \frac{\varepsilon^{2}}{k+\sqrt{v \varepsilon}}+C_{1 \varepsilon} \frac{\varepsilon}{k} C_{3 \varepsilon} G_{b},
\end{aligned}
$$

where $k$ is the turbulent kinetic energy; $\varepsilon$ is the turbulent dissipation rate; and $\sigma_{k}$ and $\sigma_{\varepsilon}$ are the Prandtl number corresponding to the turbulent flow energy $k$ and the turbulent dissipation rate $\varepsilon, \sigma_{k}=1.0$ and $\sigma_{\varepsilon}=1.2 ; x_{i}$ and $x_{j}$ are the position coordinate component; $u_{i}$ is the velocity coordinate component; $v$ is the molecular kinematic viscosity coefficient; $G_{k}$ is the average velocity gradient which causes the turbulent kinetic energy $k$ generation term; $G_{b}$ is the buoyancy induced turbulent kinetic energy generation term; $Y_{M}$ is the effect of compressible turbulence fluctuation on the total dissipation rate; and $\mu_{t}$ is the turbulent viscosity coefficient, $C_{1 \varepsilon}=1.44$ and $C_{2}=1.9$.

In order to better simulate the flow near the wall, a boundary layer needs to be generated when meshing, and the height of the first layer of the boundary layer is determined by the following formula:

$$
y_{\text {wall }}=\frac{y^{+} \mu}{\mu_{\tau} \rho},
$$

where

$$
\begin{aligned}
U_{\tau} & =\sqrt{\frac{\tau_{\text {wall }}}{\rho},} \\
\tau_{\text {wall }} & =\frac{1}{2} C_{f} \rho U^{2}, \\
C_{f} & =0.027 \operatorname{Re}^{-1 / 7}, \\
\operatorname{Re} & =\frac{\rho U L}{\mu},
\end{aligned}
$$

where $\rho$ is the fluid density; $\mu$ is the dynamic viscosity coefficient; $U$ is the free flow velocity; $L$ is the characteristic length; and $y^{+}$is selected according to the standard wall function.

The turbine simulation model and grid are shown in Figure 3. In the 3D model, the turbine wall is placed in the rotating domain, and the upper and lower parts are static domains. The method of combining structured grid and unstructured grid is adopted for grid generation. The total number of grids is about 400000 , skewness is less than 0.89 , aspect ratio is less than $5: 1$, and growth rate is 1.13 . The number and quality of grid meet the requirements of simulation accuracy.

\section{Results and Discussion}

The stress contour and streamline diagram of the turbine when the turbine speed is stable are shown in Figure 4. It is known from the stress distribution of the blade that the fluid pressure above the turbine is large, the turbine bears a large pressure on the upper part of the blade, and the vortex is formed under the fluid domain of the turbine. Conventional turbine mechanisms, such as wind turbines and water turbines, often use the momentum-blade theory to analyze the forces on the turbine. In the analysis, the momentum change caused by fluid impact is usually ignored; that is, the impact force is ignored. However, relevant researchers pointed out that when the turbine size becomes smaller, the force on the turbine due to fluid impact cannot be ignored. Therefore, the turbine force is composed of three parts: impact force, pressure drag, and friction resistance. The impact force is caused by the change of fluid momentum, while the pressure drag is caused by the pressure difference between the front and back of the blade, and the friction resistance is caused by the viscosity of the fluid. Whether the turbine rotates or not depends on whether the torque of the fluid acting on the turbine is greater than the external load. When the torque generated by the fluid is less than the external load, the turbine is stationary; when the torque generated by the fluid is greater than the external load, the turbine starts to move. The following will analyze the influence of four factors, namely, external load, blade installation angle, flow rate, and blade number, on the movement and force of turbine. 


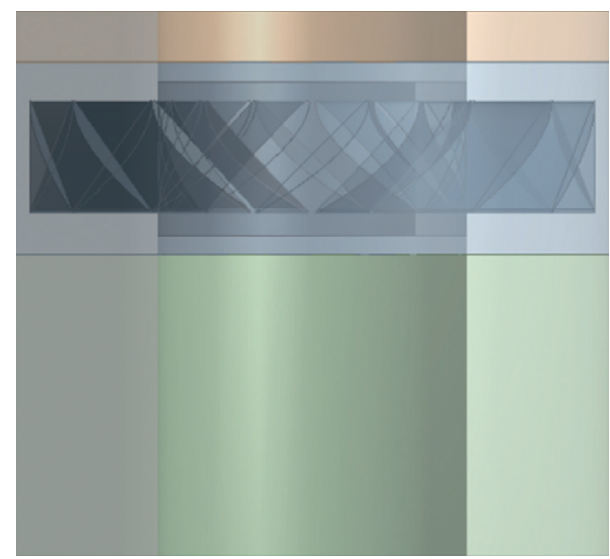

(a)

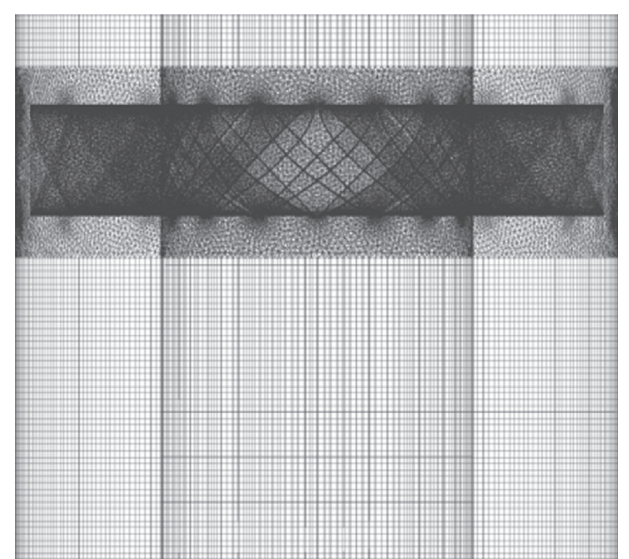

(b)

Figure 3: Downhole turbine simulation model. (a) Three-dimensional model. (b) Mesh generation.

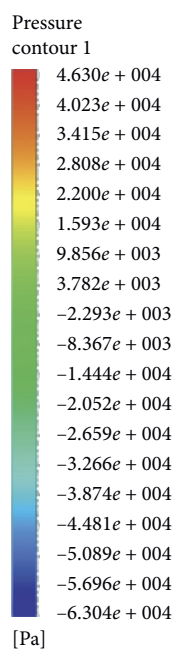

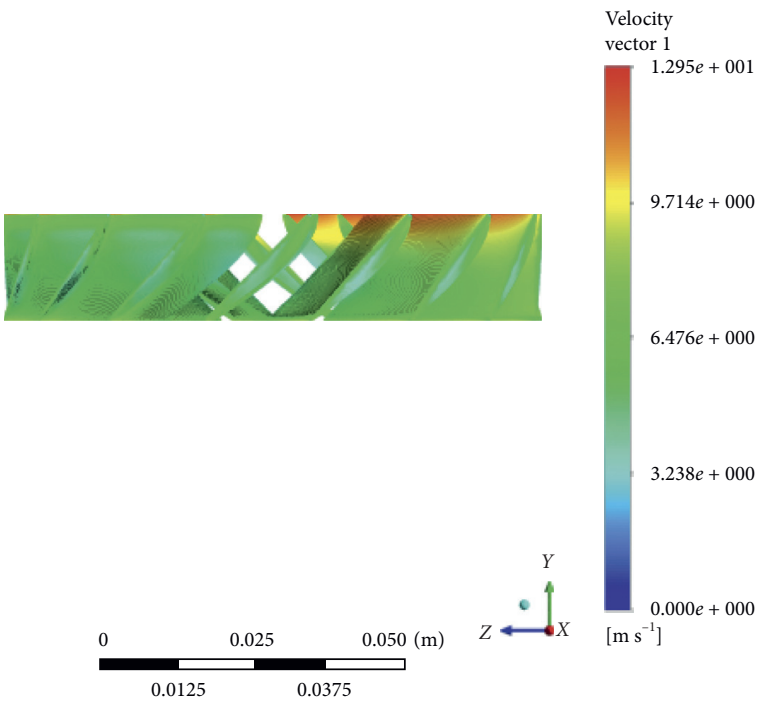

(a)

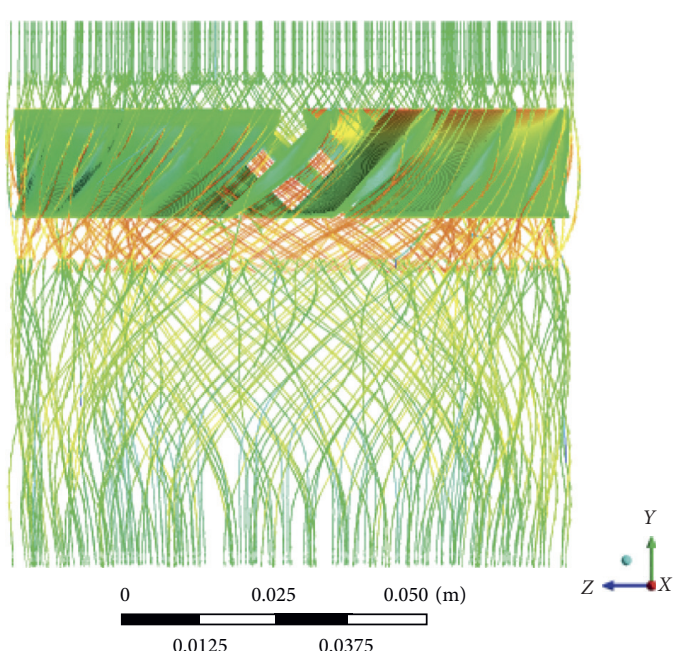

(b)

Figure 4: Turbine stress contour and streamline diagram when turbine speed is stable. (a) Pressure contour. (b) Streamline.

\subsection{Mechanical Characteristics of the Turbine}

3.1.1. Static Analysis. The moment and impact force on the turbine when it is stationary are called starting torque and initial impact force. The force on the turbine at rest determines whether the turbine can overcome the load and then moves. The influence of different factors on starting torque and initial impact force of the turbine is shown in Figure 5(a). The curve in the graph is fitted nonlinearly. As shown in Figure 5(a), under the condition of keeping the turbine structure design and fluid parameters unchanged, the change of external load on the turbine will not affect the starting torque and initial impact force when the turbine is stationary. The fitting curve is a straight line with a value of $7 \mathrm{~N} \cdot \mathrm{m}$.

As shown in Figure 5(b), the fitting results show that the change of the installation angle has four-time relationship with the starting torque and initial impact force. With the increase of the installation angle, the impact torque and initial impact force of the turbine have an increasing trend. When the installation angle of turbine blade increases, the fluid velocity and the angle of attack of the blade will change, which will lead to the change of momentum and flow field around the blade, resulting in the change of starting torque and initial impact force of turbine.

The increase of flow rate means the increase of inlet flow rate. The starting torque and initial impact force obtained under different flow conditions are fitted. It is found that the relationship between the inlet flow rate and the starting torque and impact force of turbine is quadratic, as shown in Figure 5(c). With the increase of flow rate, namely, the increase of inlet flow rate, the torque of turbine increases and amplitude rises; meanwhile, the absolute value of impact force increases with the increase of velocity and the amplitude also rises.

As shown in Figure 5(d), the starting torque and initial impact force obtained under different blade numbers are 


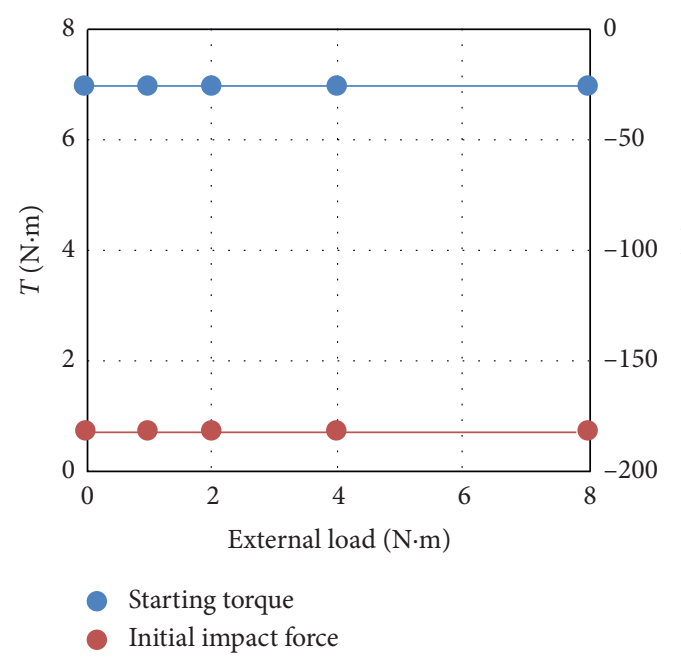

(a)

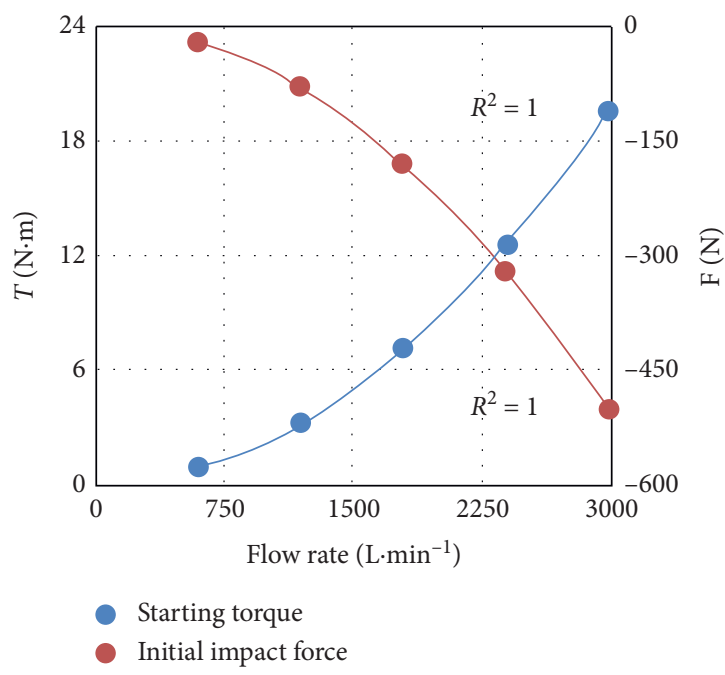

(c)

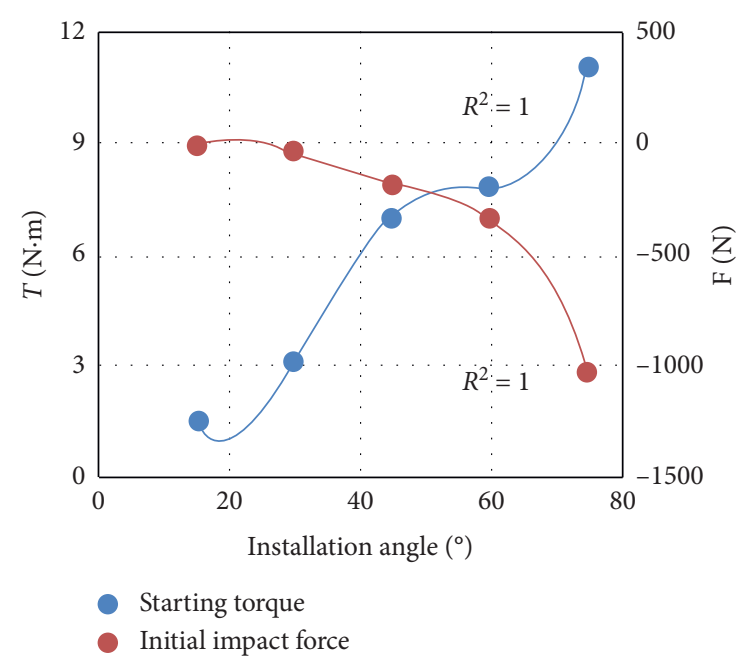

(b)

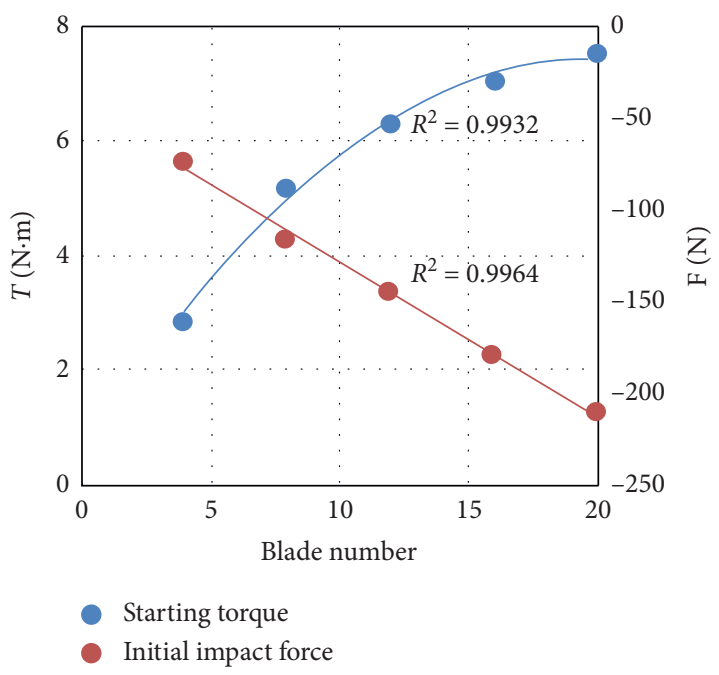

(d)

Figure 5: Effect of different factors on the starting torque and initial impact force of the turbine. (a) Pressure contour. (b) Streamline. (c) Influence of flow rate. (d) Influence of blade number.

also fitted, and it is found that the number of blades is approximately quadratic with the starting torque but linearly with the impact force.

3.1.2. Dynamic Analysis. Now, the overall analysis of the movement process of the turbine is carried out. The influence of external load, blade installation angle, flow rate, and blade number on the external torque, impact force, and angular velocity of the turbine movement process is shown in Figures 6-8 When the load of the turbine is large, the torque of the fluid acting on the turbine cannot overcome the external load. The turbine is stationary, the angular velocity is always zero, and the impact force and torque are maintained. When the torque generated by the fluid is greater than the load, the turbine starts to move, and the change of the angular velocity of the turbine is directly related to the impact torque of the turbine.
When the turbine starts to rotate from static state, its angular velocity increases continuously, which causes the angle of attack of the fluid acting on the turbine blade to change. On the one hand, it causes the flow field around the blade to change and the projection of the resistance and lift force on the blade to change in the vertical direction; on the other hand, it causes the momentum change when the fluid impacts the turbine blade, and finally impact force and hydraulic moment of the turbine change with the attack angle. The speed is constantly changing. When the torque generated by the fluid is equivalent to the external load, the total external moment of the turbine is zero and the turbine speed no longer changes. As a result, the flow field tends to be stable, and the angular velocity, impact torque, and impact force of the turbine are stable.

(1) Turbine Angular Velocity Variation. The influence of external load, blade installation angle, flow rate, and blade number on turbine angular velocity is shown in Figure 6. 


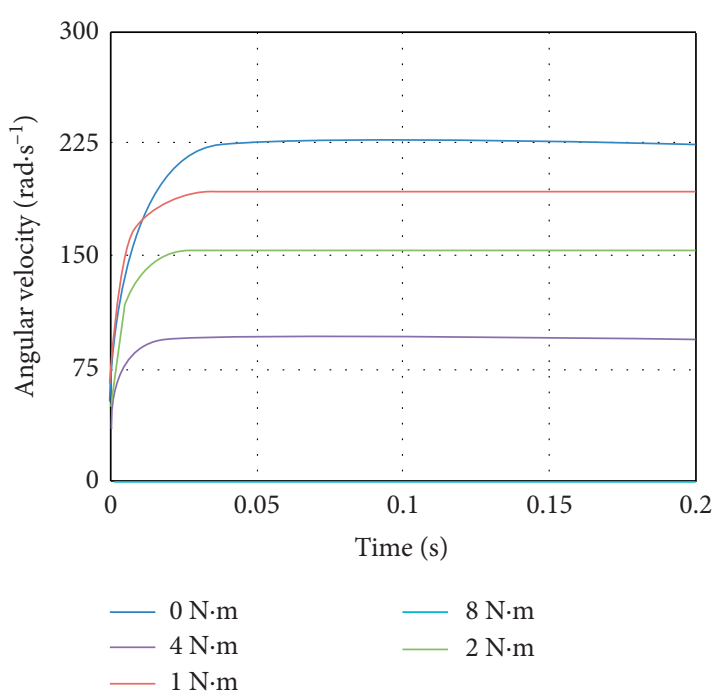

(a)

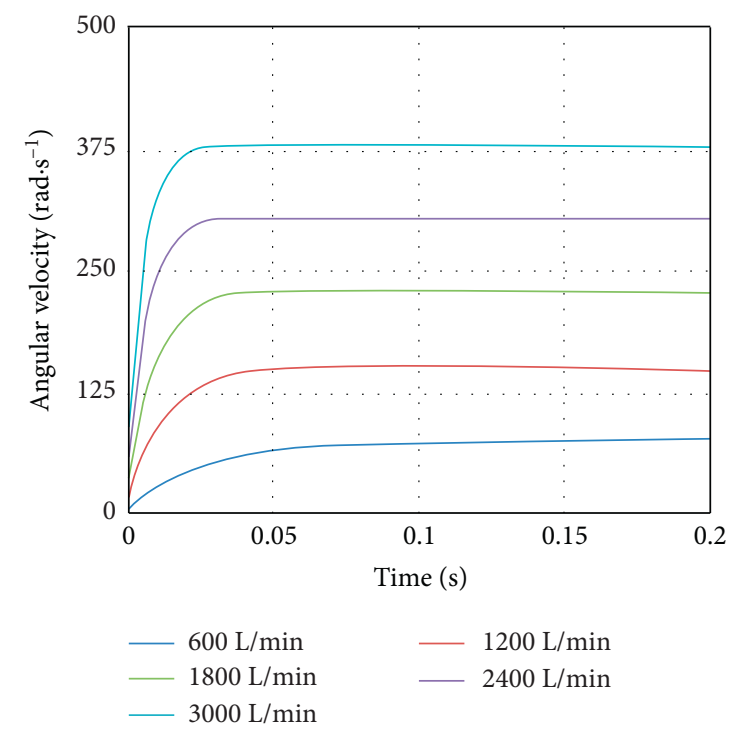

(c)

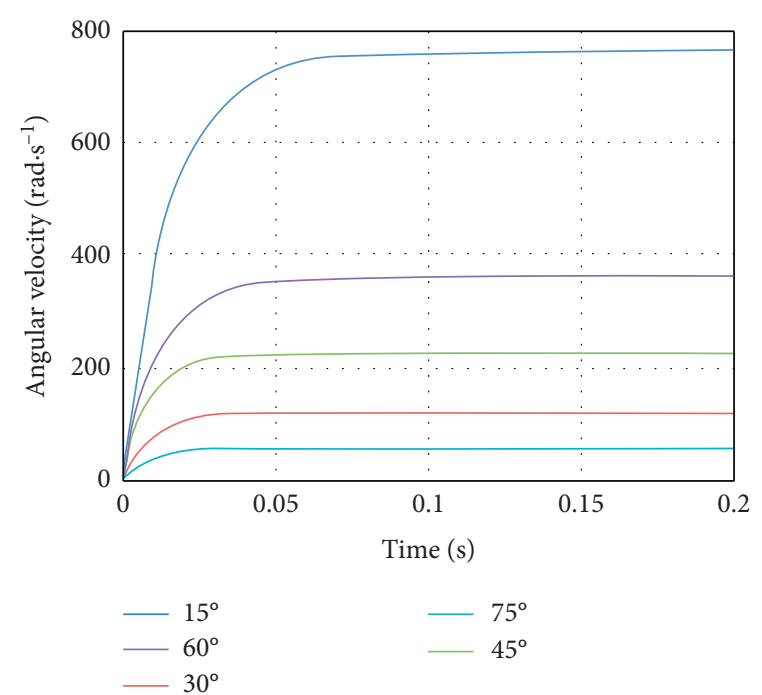

(b)

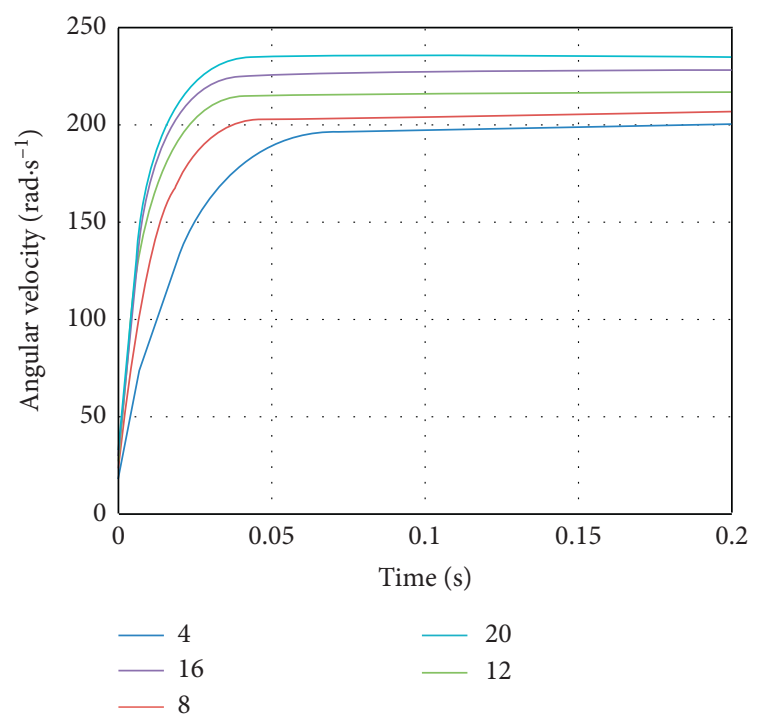

(d)

FIGURE 6: Effects of different factors on turbine angular velocity. (a) Influence of external load. (b) Influence of blade installation angle. (c) Influence of flow rate. (d) Influence of blade number.

Under different conditions, the change rule of turbine angular velocity with time is the same, turbine angular velocity increases with time, and the final speed is constant. When the external load is $8 \mathrm{~N} \cdot \mathrm{m}$, the external load is greater than the starting torque of the turbine, so the turbine stays still. The larger the installation angle of turbine, the larger the stable speed of turbine, and the longer the stability time; the larger the inlet flow, the larger the stable speed of turbine, and the shorter the stability time. However, the increase of the inlet flow leads to the increase of the erosion intensity of the drilling fluid to the turbine, and ultimately the service life of turbine is reduced. The more the number of blades, the higher the stability speed of turbine, and the shorter the stability time. The increase in the number of blades will affect the flow distribution. The more the blades, the more stable the fluid flow field. However, the high number of blades leads to an increase in rotation speed, and the pressure difference between the upper and lower turbines increases, which is not conducive to the flow of drilling fluid.

(2) Turbine Impact Force Variation. The influence of flow rate, external load, blade installation angle, and blade number on turbine impact force is shown in Figure 7. The impact force of turbine has the same change trend with time, which increases first and then stabilizes. The change of turbine impact force is closely related to the change of turbine rotation speed. With the increase of turbine rotation speed, the absolute value of impact force becomes smaller. 


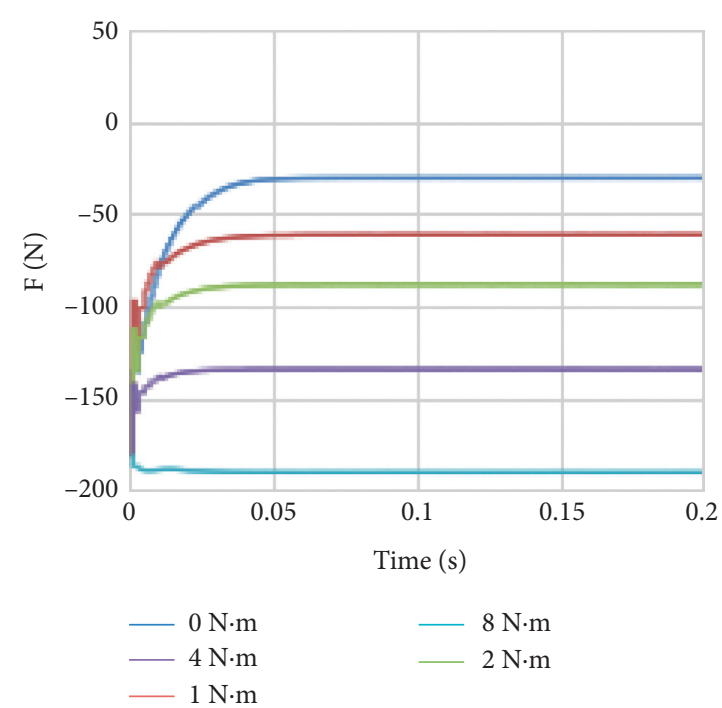

(a)

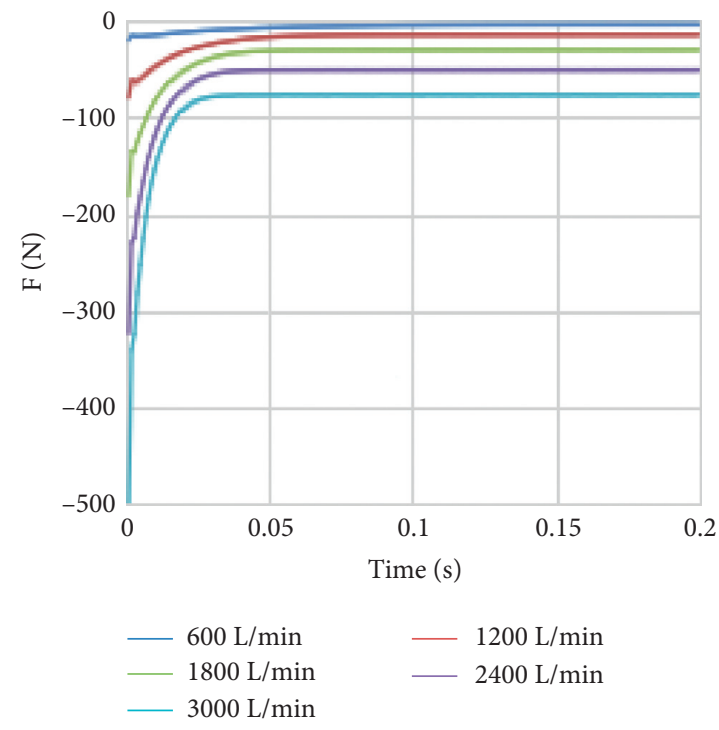

(c)

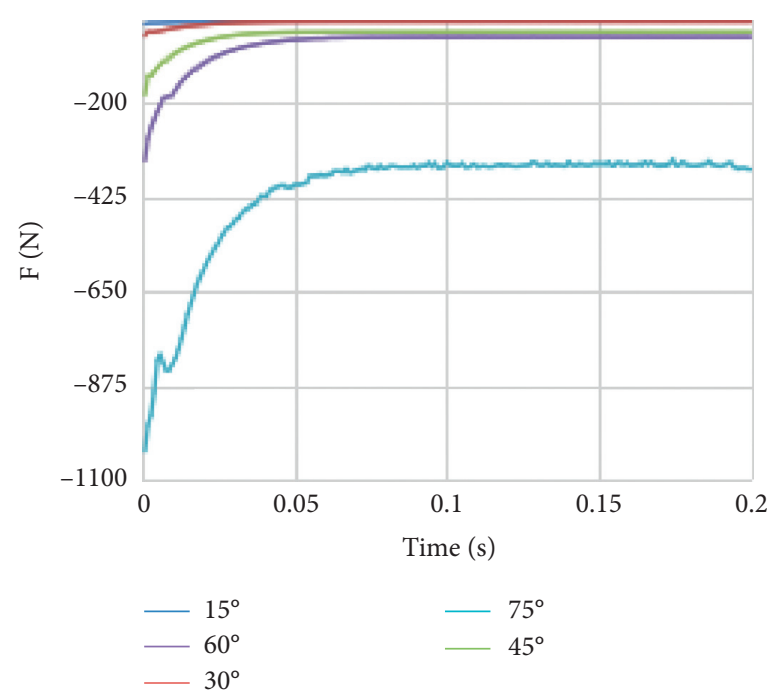

(b)
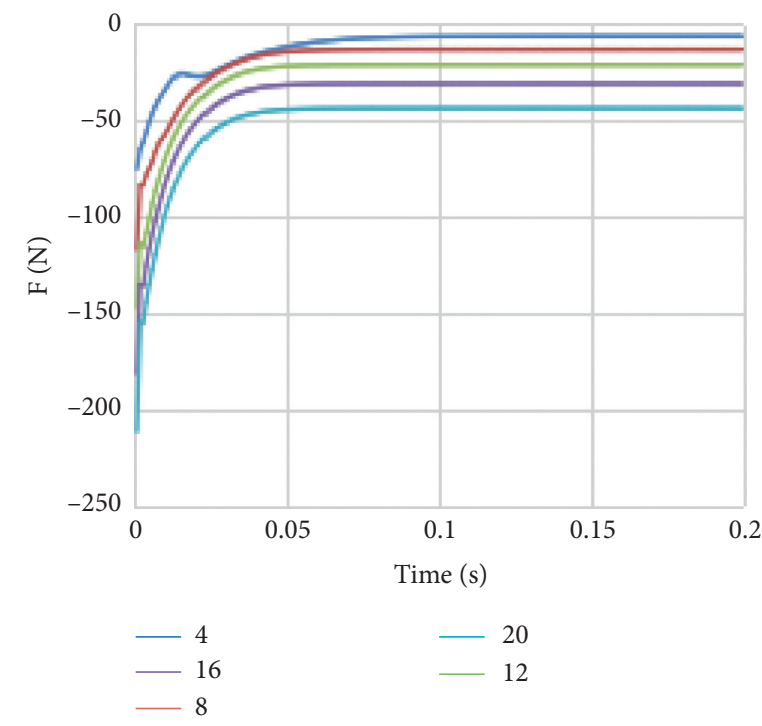

(d)

FiguRE 7: Effects of different factors on turbine impact force. (a) Influence of external load. (b) Influence of blade installation angle. (c) Influence of flow rate. (d) Influence of blade number.

With the increase of flow rate, external load, installation angle, and number of blades, the absolute value of impact force decreases when it is stable. When the external load of the turbine is $8 \mathrm{~N} \cdot \mathrm{m}$, the impact force of the turbine remains unchanged, because the starting torque of the turbine is smaller than the external load of the turbine; that is, the turbine stays still.

(3) Turbine Torque Variation. Under the conditions of different flow, external load, blade installation angle, and blade number, the variation trend of turbine torque with time is the same, which decreases with time until it becomes stable, as shown in Figure 8. Under the condition of different external loads, when the turbine is stable, the torque generated by the fluid is equal to the external load it receives, and the resultant torque of the turbine is zero. When the external load of the turbine is $8 \mathrm{~N} \cdot \mathrm{m}$ (lager than the starting torque), the turbine does not rotate and the torque of the turbine does not change with time. Under the condition of no external load, the torque produced by the fluid is always zero when the turbine is stable, as shown in Figures 8(b)$8(\mathrm{~d})$.

In CFD analysis and calculation, the basic fluid parameters are density $1000 \mathrm{~kg} / \mathrm{m}^{3}$, viscosity $10 \mathrm{mPa} \cdot \mathrm{s}$, and flow $30 \mathrm{~L} / \mathrm{s}$. The predicted mechanical characteristic curve is shown in Figure 9. 


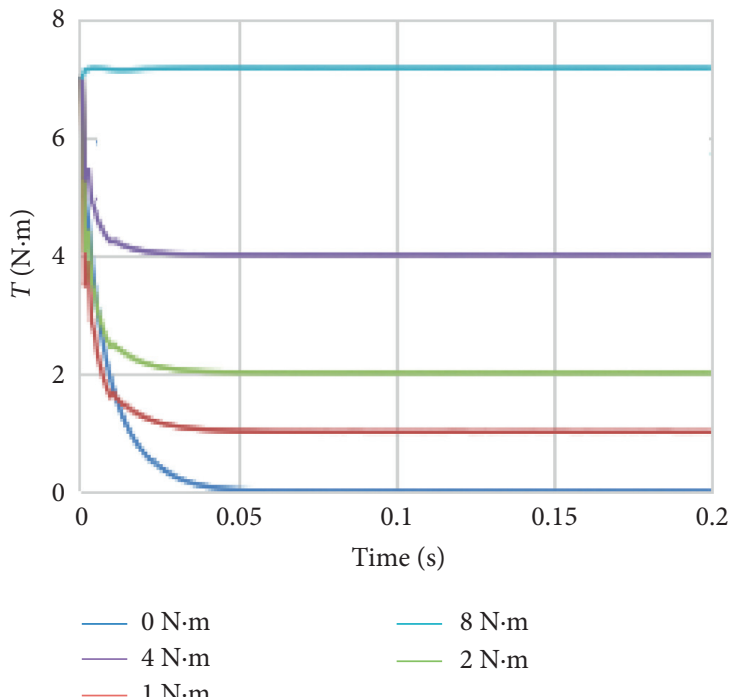

(a)

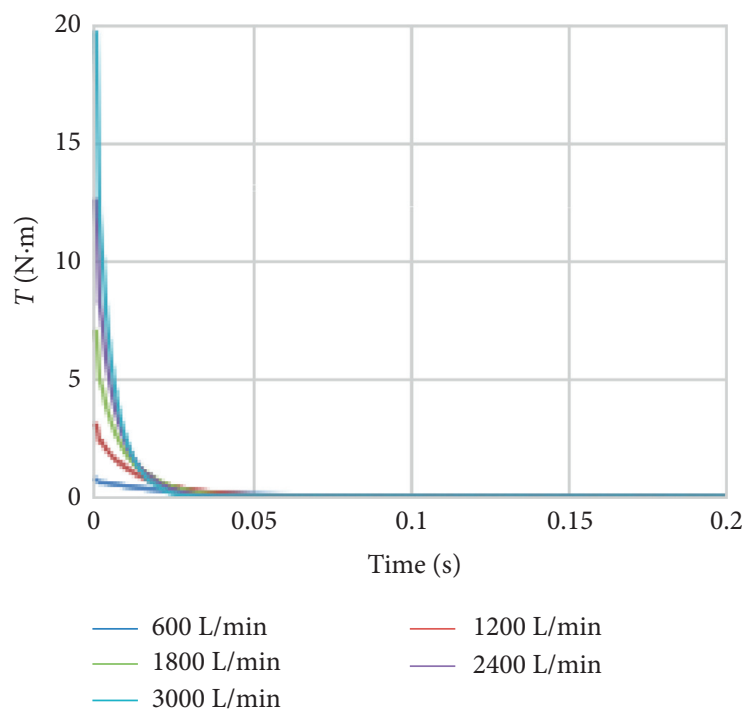

(c)

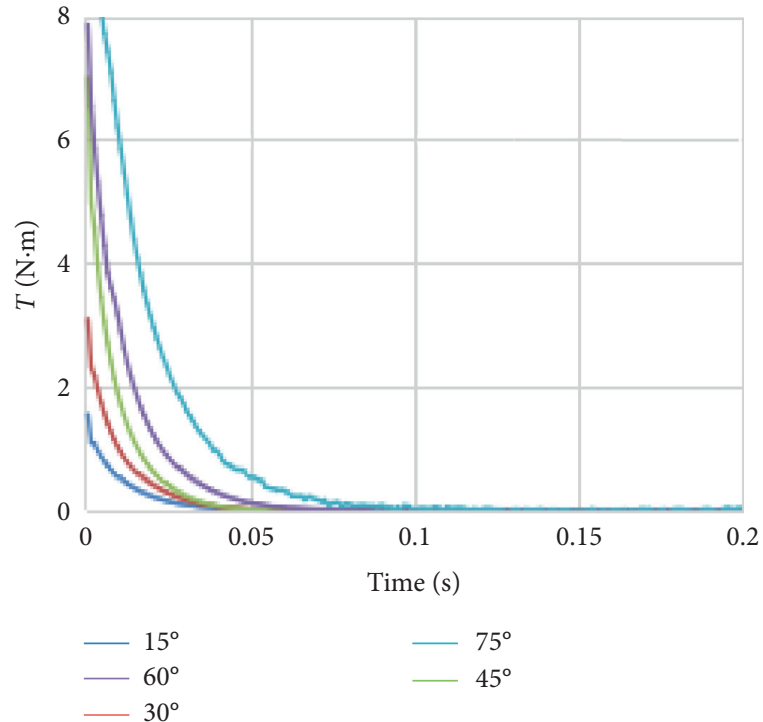

(b)

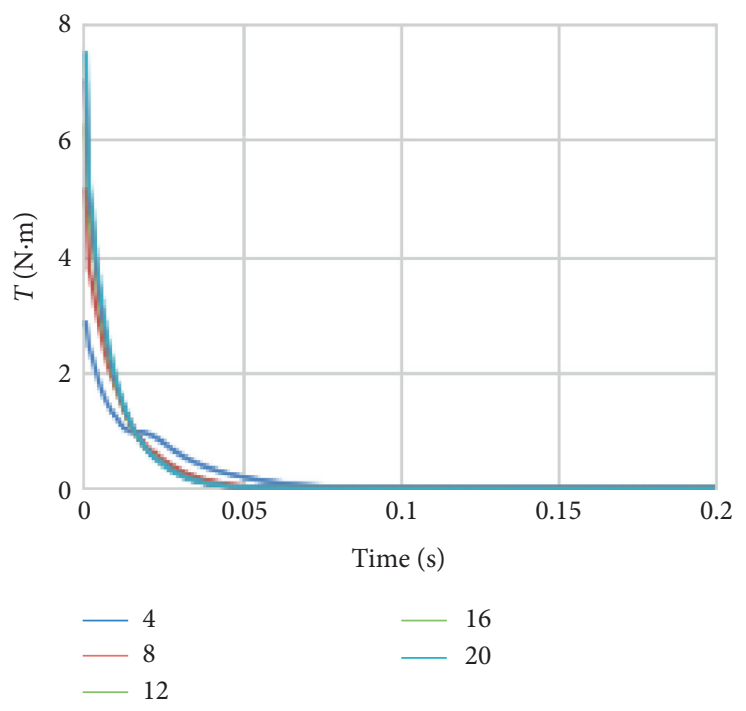

(d)

Figure 8: Effects of different factors on turbine torque. (a) Influence of external load. (b) Influence of blade installation angle. (c) Influence of flow rate. (d) Influence of blade number.

3.2. Effect of Solid Content on Turbine Performance. Figure 10 shows the streamline diagram of liquid phase and solid phase of the turbine. In the simulation, the solid phase and the liquid phase have the same inlet velocity, but when the turbine works, the solid phase and the liquid phase have different velocity distribution, and the flow velocity distribution range of the solid phase is smaller than that of the liquid phase. The pressure drop of the turbine depends on the change of fluid momentum caused by the impact of solid and liquid phases on turbine blades. Under different solid phase conditions, the flow field of solid-liquid two-phase caused by the turbine rotation is different, and the pressure drop and torque of the turbine will change.
The effect of different solid content on the performance of the turbine is shown in Figure 11. With the increase of solid content, the proportion of solid phase in the solidliquid two-phase flow increases, and more solid particles in the flow field interact with the blades of the turbine. With the increase of solid content, the pressure drop and torque increase continuously, and then the input and output power increase. It can be seen from the figure that the efficiency curve of the turbine shows an upward trend, but its linear slope decreases gradually, which shows that the working efficiency of the turbine increases with the increase of solid content and increase amplitude of efficiency decreases.

The effect of solid density on turbine performance is 


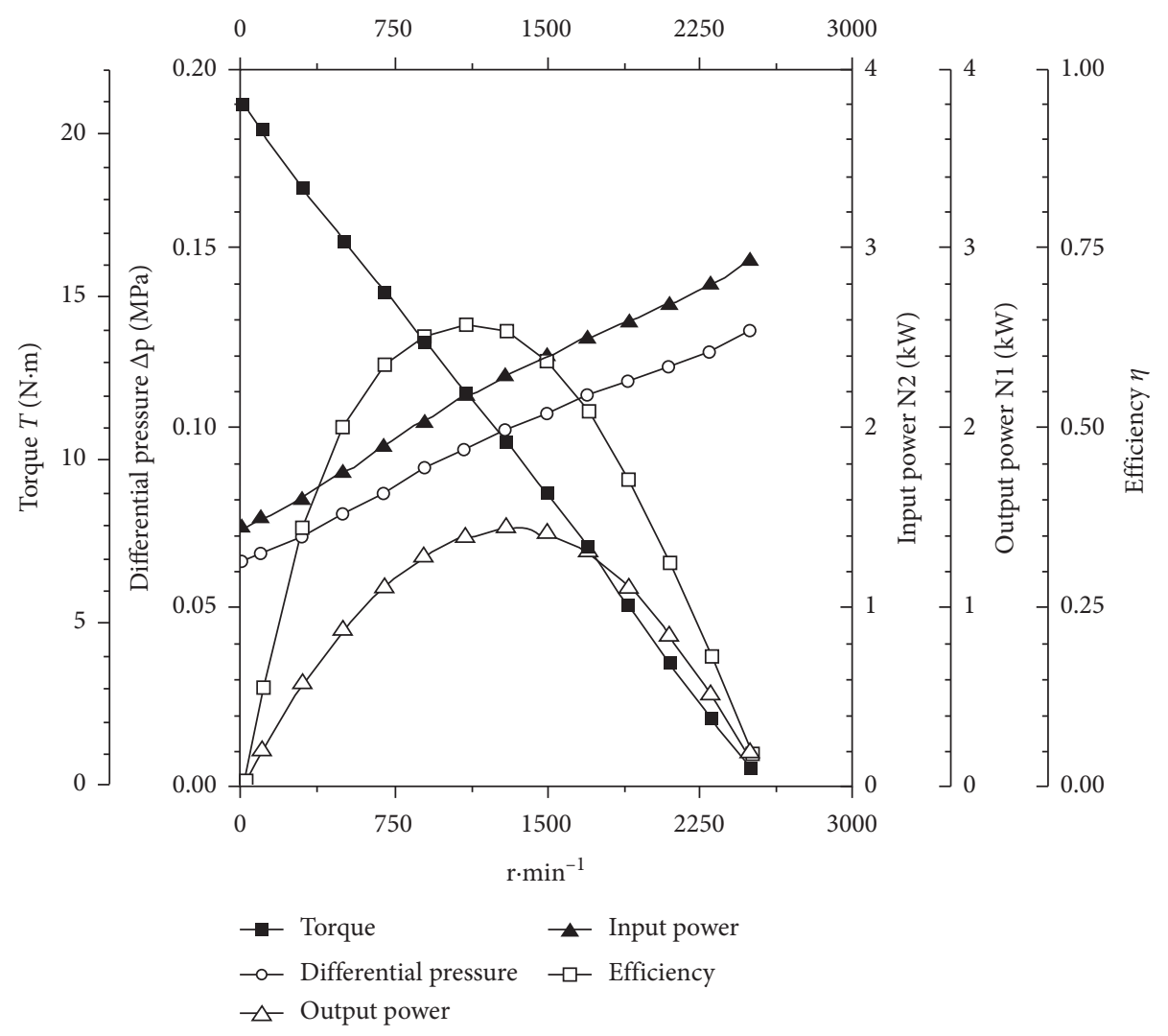

FIgURE 9: Mechanical property prediction curve of a single turbine section.
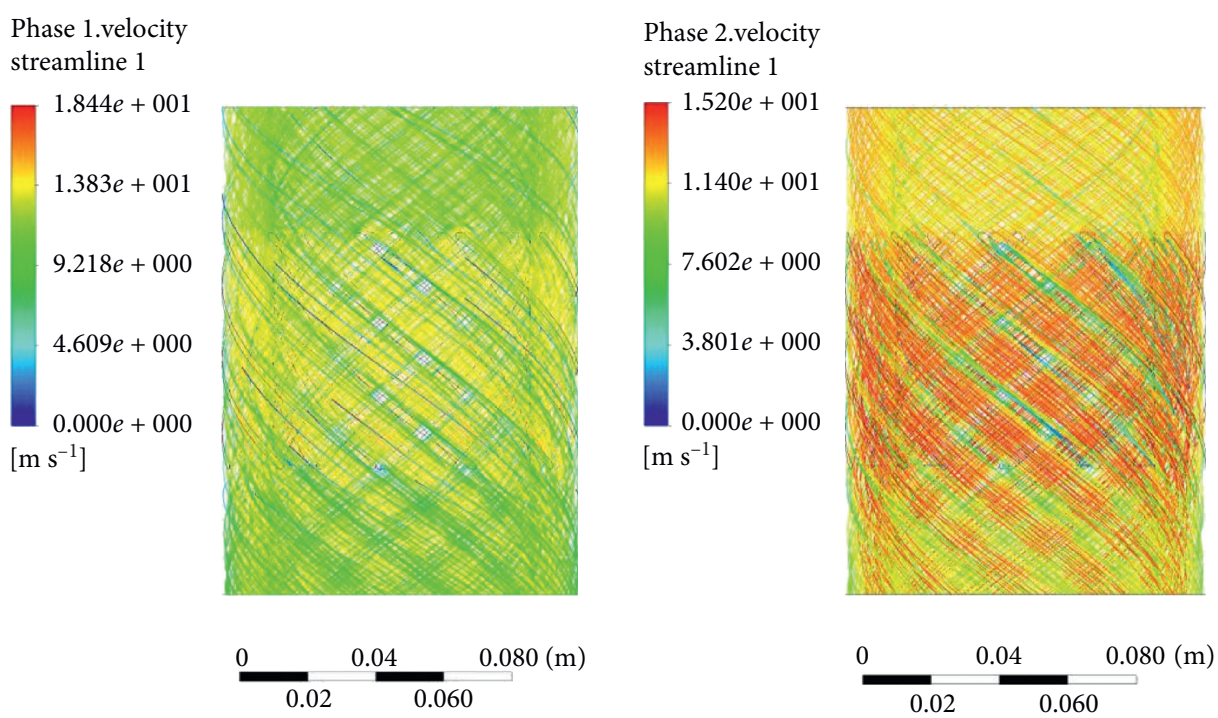

Figure 10: Turbine generator liquid phase (a) and solid phase (b) streamlines.

shown in Figure 12. Although the inlet velocity is constant, the kinetic energy of particles increases with the increase of solid density. The impact of solid on turbine is more severe. It is shown that the torque, pressure drop, and input and output power of the turbine increase linearly with the increase of solid density. The efficiency increases with the increase of solid density, but the increase amplitude also decreases.

The effect of solid particle size on turbine performance is shown in Figure 13. In the case of constant solid density 


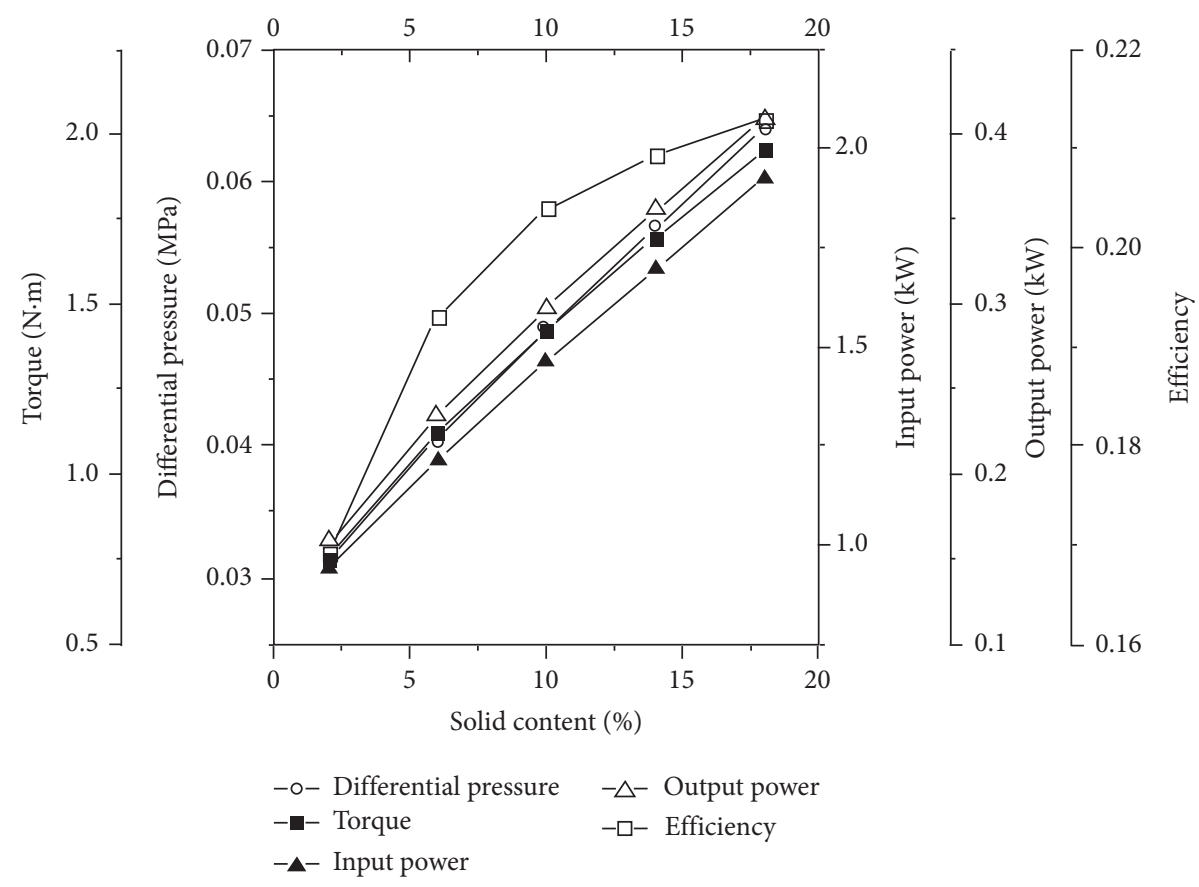

FIgURE 11: The influence of solid content on the performance of turbine generator.

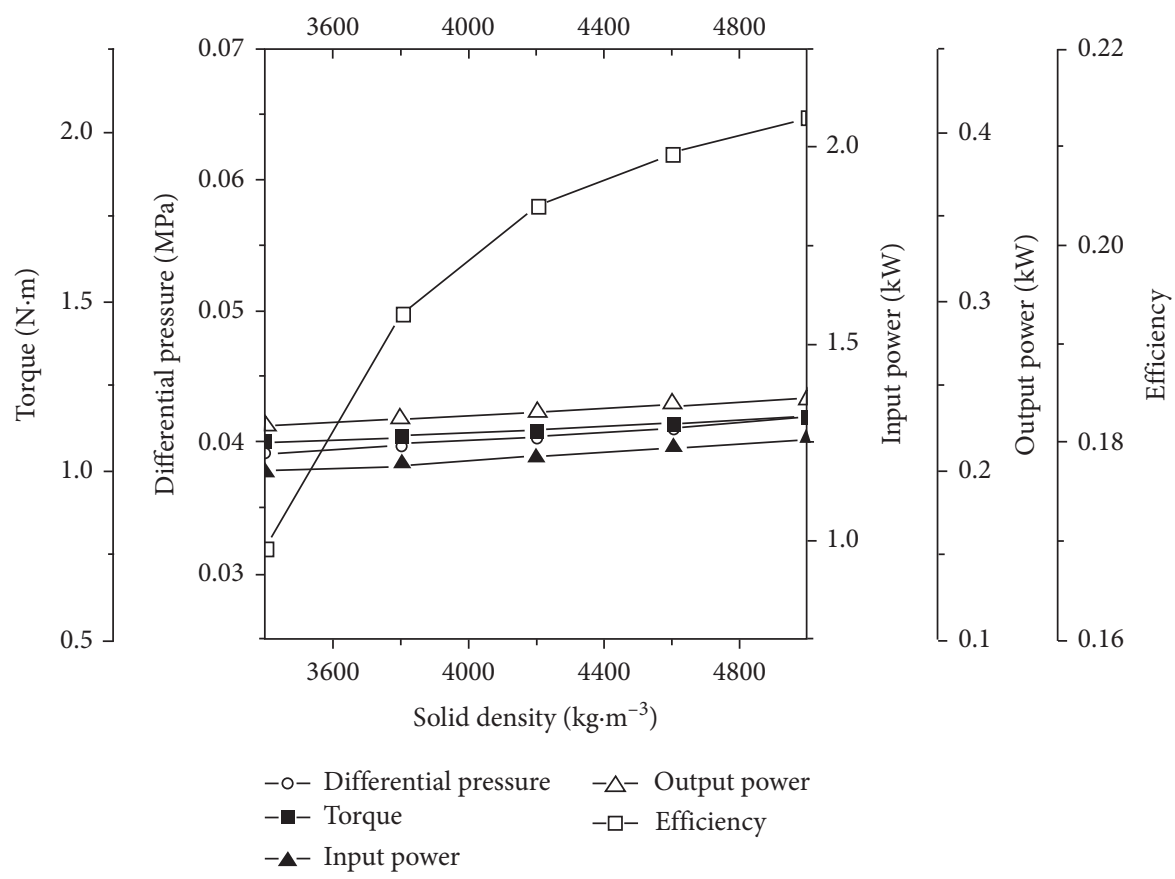

FIGURE 12: Effect of solid phase density on turbine generator performance.

and solid content, the increase of solid particle size substantially leads to the decrease of the number of particles entering the fluid domain. Although the inlet velocity is constant, the kinetic energy of single particle increases with the increase of particle size. The change of solid particle size will cause the change of particle number and kinetic energy, which will lead to different results of two-phase flow impacting turbine blades. According to the figure, with the increase of solid particle size, the pressure drop and torque of turbine first increase; with the further increase of particle size, the pressure drop and torque of turbine tend to be stable. The change trend of turbine input and output power is the same as that of pressure drop and torque. The efficiency increases with the increase of solid particle size, and the increase amplitude decreases. 


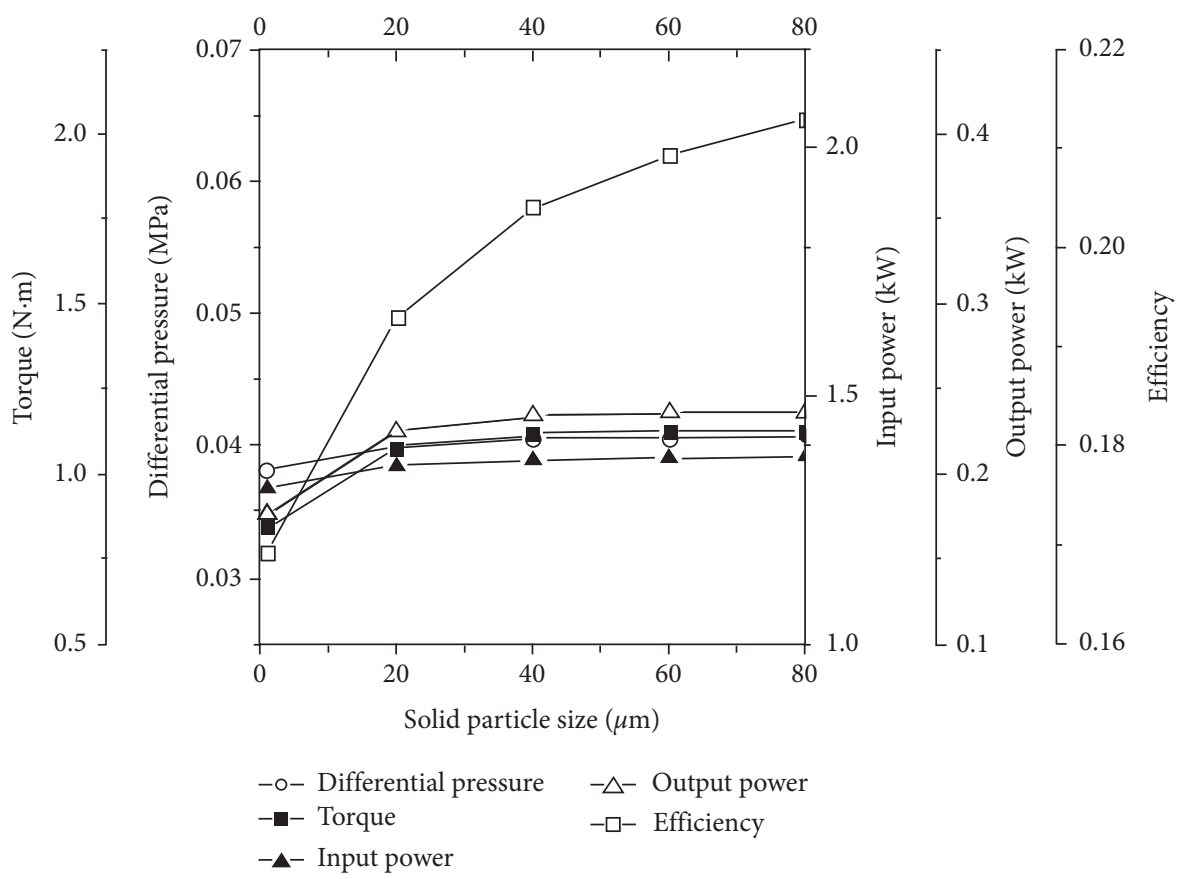

FIGURE 13: Effect of solid phase particle size on the performance of turbine generator.

\section{Conclusion}

Turbine is a common mechanical structure in drilling industry, which is usually used in downhole turbogenerator, turbodrill, and so on. With the continuous development and innovation of computational fluid dynamics (CFD) theory and numerical methods, CFD method has been become an important means for the study of downhole turbine performance. At present, the research on downhole turbines is static. In this paper, by using FLUENT software and sliding mesh method, UDF file is compiled to simulate the dynamic performance of downhole turbine. The effects of external load, number of blades, flow rate, and blade installation angle on the hydrodynamic performance of downhole turbine are studied, and the start-up characteristics and movement process of downhole turbine are analyzed. The results show that when the start-up moment is less than the load, the turbine is stationary; when the start-up moment is greater than the load, the turbine starts to rotate. In the process of the turbine's rotation, the force moment of the turbine decreases, while the speed and impact force increase continuously. When the rotational velocity is stable, the torque produced by the fluid is balanced with the load, and the impact force is stable.

Solid phase of drilling fluid will affect the performance of downhole turbogenerator. Based on Eulerian multiphase flow model and FLUENT software, three-dimensional numerical simulation of turbogenerator is carried out. The effects of solid content, particle size, and solid density of drilling fluid on the performance of downhole turbogenerator are studied. The simulation results show that, with the increase of solid phase content, the pressure drop, torque, input and output power, and efficiency of turbogenerator increase; with the increase of solid particle size, the pressure drop, torque, and input and output power of turbogenerator increase first and then stabilize, while the efficiency increases gradually and the increase decreases; with the increase of solid density, the pressure drop, torque, input and output power, and efficiency of turbogenerator increase linearly, and the efficiency increase decreases gradually.

\section{Data Availability}

The data in the tables used to support the findings of this study are included within the article. The data in the figures used to support the findings of this study are available from the corresponding author (wjzym286@163.com) upon request.

\section{Conflicts of Interest}

The authors declare that they have no conflicts of interest.

\section{Acknowledgments}

This study was supported by the Open Fund of State Key Laboratory of Shale Oil and Gas Enrichment Mechanisms and Effective Development (10010099-19-ZC0607-0048), the Natural Science Foundation of China (51704264), and the Fundamental Research Funds for the Central Universities (2-9-2018-096).

\section{References}

[1] T. Phengpom, Y. Kamada, T. Maeda, J. Murata, S. Nishimura, and T. Matsuno, "Study on blade surface flow around wind turbine by using LDV measurements," Journal of Thermal Science, vol. 24, no. 2, pp. 131-139, 2015. 
[2] D. R. Giosio, A. D. Henderson, J. M. Walker et al., "Physicsbased hydraulic turbine model for system dynamic studies," IEEE Transactions on Power Systems, vol. 32, no. 2, pp. 1161-1168, 2016.

[3] A. Amini and X. Peng, "Design of turbine system for positive mud-pulse telemetry," in Proceeings of the ASME Turbo Expo 2017: Turbomachinery Technical Conference and Exposition, American Society of Mechanical Engineers (ASME), Charlotte, NC USA, pp. 1-9, June 2017.

[4] M. Mosbahi, A. Ayadi, Y. Chouaibi, Z. Driss, and T. Tucciarelli, "Performance improvement of a novel combined water turbine," Energy Conversion and Management, vol. 205, Article ID 112473, 2020.

[5] W. Stanek, L. Czarnowska, W. Gazda, and T. Simla, "Thermoecological cost of electricity from renewable energy sources," Renewable Energy, vol. 115, pp. 87-96, 2018.

[6] A. K. Jorgenson, A. Alekseyko, and V. Giedraitis, "Energy consumption, human well-being and economic development in central and eastern European nations: a cautionary tale of sustainability," Energy Policy, vol. 66, pp. 419-427, 2014.

[7] Y. Xue, J. Shang, J. Yang, and Z. Wang, "A new converter for improving efficiency of multi-actuators fluid power system," Journal of Mechanical Science and Technology, vol. 30, no. 5, pp. 2273-2281, 2016.

[8] K. Amundson, J. Raade, N. Harding, and H. Kazerooni, "Development of hybrid hydraulic-electric power units for field and service robots," Advanced Robotics, vol. 20, no. 9, pp. 1015-1034, 2006.

[9] S. Seok, A. Wang, Y. C. Meng, D. Otten, J. Lang, and S. Kim, "Design principles for highly efficient quadrupeds and implementation on the MIT Cheetah robot," in Proceedings of the IEEE International Conference on Robotics and Automation (ICRA), pp. 3307-3312, Karlsruhe, Germany, May 2013.

[10] D. Powell, A. Ebrahimi, S. Nourbakhsh, M. Meshkahaldini, and A. M. Bilton, "Design of pico-hydro turbine generator systems for self-powered electrochemical water disinfection devices," Renewable Energy, vol. 123, pp. 590-602, 2018.

[11] U. Dorji and R. Ghomashchi, "Hydro turbine failure mechanisms: an overview," Engineering Failure Analysis, vol. 44, pp. 136-147, 2014.

[12] H. Liu, W. Wang, Y. Wen, L. Mao, W. Wang, and H. Mi, “A novel axialflow self-rectifying turbine for use in wave energyconverters," Energy, vol. 189, p. 11625, 2019.

[13] I. Eker, "Hydro turbine speed control using robust cascade governor controllers," European Transactions on Electrical Power, vol. 14, no. 5, pp. 293-310, 2004.

[14] Q. A. Li, T. Maeda, Y. Kamada, J. Murata, K. Furukawa, and M. Yamamoto, "The influence of flow field and aerodynamic forces on a straight-bladed vertical axis wind turbine," Energy, vol. 111, pp. 260-271, 2016.

[15] M. Ge, D. Tian, and Y. Deng, "Reynolds number effect on the optimization of a wind turbine blade for maximum aerodynamic efficiency," Journal of Energy Engineering, vol. 142, no. 1, Article ID 04014056, 2014.

[16] T. H. Hansen, "Airfoil optimization for wind turbine application," Wind Energy, vol. 21, no. 7, pp. 502-514, 2018.

[17] G. Paniagua, M. C. Iorio, N. Vinha, and J. Sousa, "Design and analysis of pioneering high supersonic axial turbines," International Journal of Mechanical Sciences, vol. 89, pp. 65-77, 2014.

[18] B. Pereiras, P. Valdez, and F. Castro, "Numerical analysis of a unidirectional axial turbine for twin turbine configuration," Applied Ocean Research, vol. 47, pp. 1-8, 2014.
[19] S. Kwon, J. Chung, and H. H. Yoo, "Transient vibration characteristics of a rotating multi-packet blade system excited by multiple nozzle forces," International Journal of $\mathrm{Me}$ chanical Sciences, vol. 83, pp. 76-90, 2014.

[20] G. Müller, M. F. Jentsch, and E. Stoddart, "Vertical axis resistance type wind turbines for use in buildings," Renewable Energy, vol. 34, no. 5, pp. 1407-1412, 2009.

[21] R. Lanzafame and M. Messina, "Fluid dynamics wind turbine design: critical analysis, optimization and application of BEM theory," Renewable Energy, vol. 32, no. 14, pp. 2291-2305, 2007.

[22] A. A. Wells, "Fluid driven rotary transducer," British Patent Spec No 1595700, 1976.

[23] S. Shaaban, "Insight analysis of biplane Wells turbine performance," Energy Conversion and Management, vol. 59, pp. 50-57, 2012.

[24] M. Nazeryan and E. Lakzian, "Detailed entropy generation analysis of a Wells turbine using the variation of the blade thickness," Energy, vol. 143, no. 1, pp. 385-405, 2018.

[25] P. Halder and A. Samad, "Wave energy harvesting turbine: performance enhancement," Procedia Engineering, vol. 116, pp. 97-102, 2015.

[26] T. Setoguchi, S. Santhakumar, M. Takao, T. H. Kim, and K. Kaneko, "A modified Wells turbine for wave energy conversion,” Renewable Energy, vol. 28, no. 1, pp. 79-91, 2003.

[27] P. Halder and A. Samad, "Optimal Wells turbine speeds at different wave conditions," International Journal of Marine Energy, vol. 16, pp. 133-149, 2016.

[28] A. F. O. Falcão, L. M. C. Gato, J. C. C. Henriques, J. E. Borges, B. Pereiras, and F. Castro, "A novel twin-rotor radial-inflow air turbine for oscillating-water-column wave energy converters," Energy, vol. 93, no. 2, pp. 2116-2125, 2015.

[29] V. Jayashankar, S. Anand, T. Geetha et al., "A twin unidirectional impulse turbine topology for OWC based wave energy plants," Renewable Energy, vol. 34, no. 3, pp. 692-698, 2009.

[30] M. M. Aslam Bhutta, N. Hayat, M. H. Bashir, A. Rais Khan, K. Naveed Ahmad, and S. Khan, "CFD applications in various heat exchangers design: a review," Applied Thermal Engineering, vol. 32, pp. 1-12, 2012.

[31] Y. Wang, K. Williams, M. Jones, and B. Chen, "CFD simulation methodology for gas-solid flow in bypass pneumatic conveying-a review," Applied Thermal Engineering, vol. 125, pp. 185-208, 2017.

[32] P. Halder, A. Samad, and D. Thevenin, "Improved design of a Wells turbine for higher operating range," Renewable Energy, vol. 106, pp. 122-134, 2017. 